\title{
Intraspecific trait changes have large impacts on community functional composition but do not affect ecosystem function
}

\author{
Noémie A. Pichon ${ }^{1,2} \odot$ | Seraina L. Cappelli ${ }^{2,3} \odot \mid$ Eric Allan $^{2,4} \odot$
}

${ }^{1}$ Department of Ecology and Genetics, University of Oulu, Oulu, Finland

${ }^{2}$ Institute of Plant Sciences, University of Bern, Bern, Switzerland

${ }^{3}$ Research Centre for Ecological Change, University of Helsinki, Helsinki, Finland

${ }^{4}$ Centre for Development and the Environment, University of Bern, Bern, Switzerland

\section{Correspondence}

Noémie A. Pichon

Email: noemie.pichon@oulu.fi

\section{Funding information}

Schweizerischer Nationalfonds zur Förderung der Wissenschaftlichen Forschung, Grant/Award Number: 31003A_160212

Handling Editor: Renske Onstein

\section{Abstract}

1. Plant functional traits can provide a mechanistic understanding of community responses to global change and of community effects on ecosystem functions. Nitrogen enrichment typically shifts trait composition by promoting the dominance of acquisitive plants (high specific leaf area [SLA] and low leaf dry matter content [LDMC]), translating into high biomass production. Changes in mean trait values can be due to shifts in species identity, relative abundances and/or intraspecific trait values. However, we do not know the relative importance of these shifts in determining trait responses to environmental changes, or trait effects on ecosystem functioning, such as biomass production.

2. We quantified the relative importance of species composition, abundance and intraspecific shifts in driving variation in SLA and LDMC, and how these shifts affected above- and below-ground biomass. We measured traits in a grassland experiment manipulating nitrogen fertilisation, plant species richness, foliar fungal pathogen removal and sown functional composition (slow vs. fast species). We fitted structural equation models to test the importance of abundance and intraspecific shifts in determining (a) responses of functional composition to treatments and (b) effects on above- and below-ground biomass.

3. We found that species intraspecific shifts were as important as abundance shifts in determining the overall change in functional composition (community weighted mean trait values), and even had large effects compared to substantial initial variation in sown trait composition. Intraspecific trait shifts resulted in convergence towards intermediate SLA in diverse communities; although convergence was reduced by nitrogen addition and enhanced by pathogen removal. In contrast, large intraspecific shifts in LDMC were not influenced by the treatments. However, despite large responses, intraspecific trait shifts had no effect on above- or below-ground biomass. Only interspecific trait variation affected functioning: below-ground biomass was reduced by SLA and increased by LDMC, while above-ground biomass was increased by SLA.

4. Synthesis. Our results add to a growing body of literature showing large intraspecific trait variation and emphasise the importance of using field collected data to

This is an open access article under the terms of the Creative Commons Attribution License, which permits use, distribution and reproduction in any medium, provided the original work is properly cited.

(C) 2022 The Authors. Journal of Ecology published by John Wiley \& Sons Ltd on behalf of British Ecological Society 
determine community functional composition. However, they also show that intraspecific variation does not necessarily affect ecosystem functioning and therefore response-effect trait relationships may differ between versus within species.

KEYWORDS

above-ground-below-ground biomass, functional traits, fungal pathogens, grassland, LDMC, nitrogen enrichment, SLA, species richness

\section{1 | INTRODUCTION}

Nitrogen enrichment is a major global change factor (Battye et al., 2017). It affects ecosystem functioning directly, by increasing nutrient levels and lowering soil pH, (Bobbink et al., 2010; Sardans et al., 2012; Vitousek et al., 1997), and indirectly by changing the biotic community (de Vries et al., 2012; Lavorel \& Grigulis, 2012; Stevens, 2004; Suding et al., 2005). Plant communities respond strongly, and species composition and individual abundances shift dramatically following nitrogen enrichment.

The use of functional traits has revolutionised community ecology and allowed a more mechanistic and predictive understanding of these compositional shifts and therefore of how plant communities respond to global change (Allan et al., 2015; Lavorel \& Grigulis, 2012; McGill et al., 2006; de Vries et al., 2012). At the same time functional traits have been shown in many studies to be good predictors of ecosystem functioning (Allan et al., 2015; Cappelli et al., 2020; Díaz et al., 2007; Lavorel \& Grigulis, 2012; Pichon, Cappelli, Soliveres, Hölzel, et al., 2020; Ratcliffe et al., 2017; Roscher et al., 2013), although weaker effects have also been observed (van der Plas et al., 2020). Mean plant trait values therefore simultaneously respond to global changes and affect ecosystem functioning, and changes in functional trait composition may be a major mechanism explaining global change effects on functioning (Allan et al., 2015). The 'response-effect' trait framework is an attempt to gain a more comprehensive understanding of how changes in biotic communities will affect ecosystem functioning, by grouping functional traits into those that determine the response of communities to environmental change and those that predict the effect of the communities on ecosystem functioning (Lavorel \& Garnier, 2002). Strong linkages between response and effect traits indicate that global change wil affect functioning by altering functional trait composition (Lavorel $\&$ Garnier, 2002). If we could identify the key response and effect traits, and their interrelationship, we would therefore be able to predict how global change will alter ecosystem functioning through changing functional composition.

Shifts in community functional composition in response to global change drivers can occur through three mechanisms: changes in species identity, a shift in the relative abundances of species with particular traits (hereafter abundance shift) or an intraspecific shift in traits between individuals (intraspecific shift, Lepš et al., 2011). All of these shifts may determine the overall response to environmental change and may all affect ecosystem functioning as well. Intraspecific trait shifts can occur either through plastic changes in trait expression or through genetic changes (Geber \& Griffen, 2003). It is commonly assumed that intraspecific shifts will have a smaller effect than abundance shifts on community mean trait values because interspecific variation exceeds intraspecific (Albert et al. 2011; Garnier, Laurent, et al., 2001; Siefert et al., 2015), however, experiments have revealed large intraspecific variation in certain functional traits (Albert, 2015; Jung et al., 2010; Violle et al., 2012). Intraspecific variation may be important in allowing species to track environmental variation (Henn et al., 2018) but it could respond differently to environmental gradients compared to interspecific variation (Laughlin et al., 2017), leading to decoupled responses between and within species. It therefore remains unclear how intraspecific trait shifts and abundance shifts contribute to altering response trait composition (Roscher et al., 2018). It is even less clear whether intraspecific and abundances changes are similarly important in both response and effect traits, and therefore how they simultaneously respond to environmental change and affect ecosystem functioning.

One of the key axes of plant functional trait variation, which typically responds strongly to nitrogen enrichment, is the leaf economics spectrum. It distinguishes slow-growing species, with low leaf nutrient concentrations, tough and long-lived leaves from fast-growing species, with high leaf nutrient concentrations, soft and short-lived leaves (Díaz et al., 2016; Wright et al., 2004). The position of a species along this axis is indicated by traits such as SLA and leaf dry matter content (LDMC). Increases in soil $\mathrm{N}$ levels will typically directly increase community SLA (and decrease LDMC) by favouring the establishment and growth of faster growing species (Wright et al., 2004), but also because individual plants produce leaves with higher SLA (Shipley \& Almeida-Cortez, 2003; Siefert \& Ritchie, 2016), suggesting $\mathrm{N}$ would directly alter functional composition through both intraspecific and abundance shifts. $\mathrm{N}$ enrichment could also indirectly affect functional composition, in particular, by causing a loss of plant species richness and changes in consumer abundance, for instance of fungal pathogens. A loss of species richness might drive reductions in SLA values within species due to lower light competition in open, species poor communities (Lipowsky et al., 2015). A change in the abundance of foliar fungal pathogens with $\mathrm{N}$ enrichment (Dordas, 2008) might reduce SLA if pathogens reduce the relative abundance of fast-growing species or cause species to shift trait expression towards lower SLA, due to lower investment in defence by fast species (Blumenthal et al., 2009; Cappelli et al., 2020). The responsiveness of functional composition to environmental changes could also differ between fast and slow communities, as high SLA species might show higher plasticity and intraspecific variation in SLA (Freschet et al., 
2015). It is not known whether these different aspects of $N$ enrichment alter functional composition principally through favouring species with certain traits (abundance shifts) or by causing intraspecific shifts in traits, or if the various drivers differ in whether they principally result in abundance or intraspecific shifts.

Leaf economics spectrum traits are also key effect traits and drive a number of ecosystem functions. Slow-growing communities (with low SLA and high LDMC) typically produce less above-ground biomass and have slow biogeochemical cycling, but may allocate more resources below-ground (see Freschet et al., 2015; Mahaut et al., 2020). Many studies looking at the effects of functional trait composition on ecosystem function calculate trait shifts using literature values, or measure a single mean value per species, that is, they ignore intraspecific variation, and it has been suggested that this might underestimate effects of traits on functioning (see Violle et al., 2012 and van der Plas et al., 2020). However, even if intraspecific shifts are important in determining trait responses to environmental change, it is not clear whether they also strongly affect ecosystem functioning (Albert et al., 2011). Intraspecific trait changes might not have the same effect on ecosystem functioning as interspecific shifts, because the strong correlations between leaf economic traits break down within communities (Anderegg et al., 2018; Messier et al., 2017), which could be due to lower variation in leaf life span within communities (Funk \& Cornwell, 2013) or different correlations between traits within and across species (Laughlin et al., 2017). It is therefore possible that response and effect trait correlations change within species compared to across species, that is, that intraspecific trait responses to environmental factors are decoupled from their effects on function, however, this has never been tested. It is crucial to understand the extent to which species intraspecific variation simultaneously contributes to explaining trait responses to the environment and trait effects on functioning, if we are to predict how environmental change alters ecosystem functioning.

There are only two studies, to our knowledge, which estimated the effect of trait shifts on function. However, they calculated changes in biomass for individual species (Liancourt et al., 2015), or compared models fitting community weighted means (CWMs) calculated using traits of different origins (Roscher et al., 2018). Here, we developed an approach that has the advantage of simultaneously estimating the relative response and effect of each component of the trait shifts. To quantify the extent of intraspecific and abundance shifts in response to environmental changes, and the consequences of these shifts for ecosystem functioning, we conducted a field experiment in which we manipulated environmental conditions to trigger functional trait shifts. We manipulated direct effects of $\mathrm{N}$ and two indirect effects: loss of plant species richness and changes in consumer communities (fungicide application). We further, independently manipulated the mean SLA of our communities by establishing plots with different combinations of high and low SLA species, to compare the extent of intraspecific and abundance shifts with large, initial compositional variation in SLA, and also in LDMC. We would expect the initial compositional variation to have the largest effect on variation in CWM traits. Communities were initially sown with species at equal abundance, but abundances and intraspecific trait expression could shift freely within and between communities, which allowed us to quantify: the contribution of shifts in abundance and intraspecific trait expression to changing CWM traits, whether the degree of intraspecific and abundance shifts depended on the initial (sown) trait composition and what the consequences of these shifts were for ecosystem functioning. Using structural equation models (SEMs), we first analysed trait responses to environmental change and tested how abundance and intraspecific shifts contributed to total variation in CWM SLA and LDMC. Second, we analysed trait effects on ecosystem function and tested how these shifts translated into changes in above- and below-ground biomass.

We tested the following hypothesis:

1. Responses of CWM traits to the environment are driven by both intraspecific shifts in trait expression and shifts in the relative abundance of species.

2. N enrichment, species richness and fungicide application all favour fast-growing species, that is, they increase mean SLA and decrease mean LDMC

3. Effects of CWM traits on ecosystem functioning (above- and below-ground biomass) are driven by both intraspecific shifts in trait expression and shifts in the relative abundances of species.

\section{2 | MATERIALS AND METHODS}

\section{1 | Field site}

We conducted the study in the PaNDiv experiment, a large grassland experiment located in Münchenbuchsee, Switzerland. The species composition of the original grassland, was typical for extensively managed, intermediately fertile grasslands in the Swiss lowlands, dominated by Dactylis glomerata, Lolium multiflorum, Crepis biennis, Plantago lanceolata and Trifolium sp (Figure S1, Delarze et al., 2015). The PaNDiv experiment started in autumn 2015 and manipulates plant CWM trait values, species richness, $\mathrm{N}$ enrichment and fungicide application in a full-factorial design. We assembled plant communities using a pool of 20 species common in central European grasslands. We divided the species into two groups according to their SLA and leaf $N$ content (Figure S1). The two groups were classified as having a slow (low SLA, low $\mathrm{N}$ content), or fast growth strategy (high SLA, high $\mathrm{N}$ ) and contained both herbs (six fast, six slow) and grasses (four fast, four slow). We also tried to balance fast and slow across the other two major plant families included: Asteraceae (two fast, two slow) and Apiaceae (two fast, one slow), other families contained only one or two species. Experimental communities contained one, four or eight species, and at the four and eight species levels, communities contained either slow- or fast-growing species, or a mix of both (monocultures could contain only one functional strategy). The species in each community were randomly drawn from the particular species pool (i.e. all species, slow or fast growing), for a total of 50 different combinations. This created a large gradient in mean SLA values $\left(15-29 \mathrm{~m}^{2} / \mathrm{kg}\right)$ and 
mean LDMC values (208-290 mg/g) between communities, which is comparable to trait values along a central European land use intensity gradient (SLA: 13-32 m²/kg, LDMC: 220-420 mg/g, Breitschwerdt et al., 2018). Each combination of species was grown four times; in control conditions, with $\mathrm{N}$ enrichment (100 kg N ha ${ }^{-1}$ year $^{-1}$ as urea twice a year in April and June), with fungicide application ('Score Profi', 24.8\% Difenoconazol $250 \mathrm{~g} / \mathrm{L}$, four times during the growing season) and with both $\mathrm{N}$ and fungicide together, resulting in 200 plots in total. Communities were sown with equal numbers of seeds per species, corrected for germination rates (total 1000 seedlings $/ \mathrm{m}^{2}$ ), on $2 \mathrm{~m} \times 2 \mathrm{~m}$ plots separated by a $1 \mathrm{~m}$ path. The plots were randomly distributed in four blocks, each containing every species combination, each time with a randomly assigned treatment.

The site was weeded and ploughed before the start of the experiment. To maintain the different diversity levels, we weeded each plot three times per year, in April, July and September, enabling us to keep total weed abundance to below $5 \%$ of total cover, on average. The whole field was mown in mid-June and late August and the biomass was removed, which simulates extensive grassland management in the Swiss lowlands. The carbon and nitrogen organic content of the soil were measured in June 2019 and were $2.35 \%-4.70 \%$ organic C and $0.25 \%-0.43 \%$ organic N (Walde et al., 2021). The mean volumetric water content of $5.95 \%$ indicated rather dry conditions when we collected the samples for the present study (mean from June to August 2017). Further information about the design of PaNDiv and field characteristics can be found in Pichon, Cappelli, Soliveres, Hölzel, et al. (2020).

We harvested above-ground biomass production before mowing in August 2017 on two quadrats of $20 \times 50 \mathrm{~cm}$ in the centre of each plot, clipping vegetation above $5 \mathrm{~cm}$. The samples were dried at $65^{\circ} \mathrm{C}$ for $48 \mathrm{~h}$ and weighed. Percentage cover of target species, weeds and bare ground, was recorded at the same time. Above-ground biomass production was corrected for weed cover by multiplying the biomass by the proportion of target (non-weed) species. Below-ground biomass was measured in autumn 2017 by taking two cores per plot to $20 \mathrm{~cm}$ depth (440 $\mathrm{cm}^{3}$ of soil). We homogenised the two samples and used a subset of $40 \mathrm{~g}$ fresh soil in which we washed and sorted out all roots. We then dried the roots at $65^{\circ} \mathrm{C}$ for $48 \mathrm{~h}$. To calculate below-ground biomass per $\mathrm{g}$ of dry soil, we estimated soil humidity by weighing $40 \mathrm{~g}$ of soil from the same plot before and after drying for $24 \mathrm{~h}$ at $105^{\circ} \mathrm{C}$.

\section{2 | Leaf sampling}

We collected leaf samples on the 200 plots over 2 weeks in August 2017, taking one leaf from each of five distinct individuals per species per plot. We tried to avoid sampling clonal individuals by sampling spatially distant individuals. SLA and LDMC were measured following the protocol of Garnier, Shipley, et al. (2001). We measured leaf fresh weight and recorded the leaf area with a leaf area metre (LI-3000C, LI-COR Biosciences), after overnight rehydration in deionised water in the dark. We dried the samples at $65^{\circ} \mathrm{C}$ for 2 days and measured their dry weight. We calculated SLA (area/dry

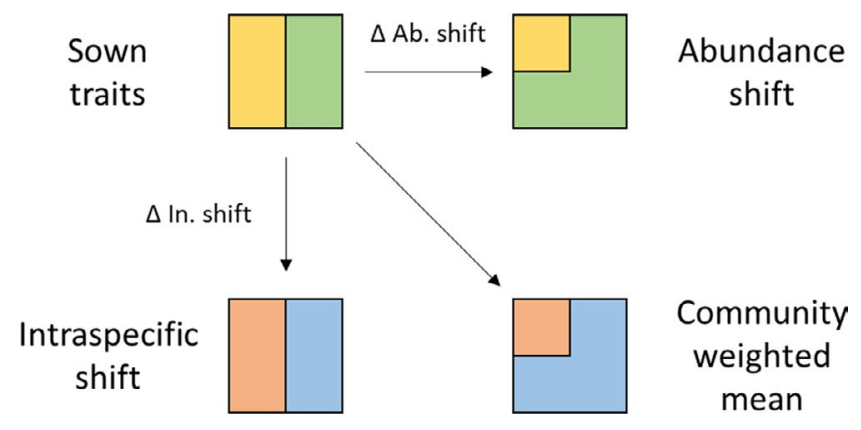

FIGURE 1 Schematic description of the components of community weighted mean (CWM) traits, for a community of two species, represented by coloured rectangles. Shifts in CWM traits are due to shifts in species relative abundances ( $\Delta$ ab. shift, represented by a change in the size of the rectangles) and to species intraspecific trait shifts ( $\Delta \mathrm{in}$. shift, represented by a change in colours)

weight) and LDMC (dry/fresh weight) per species per plot by averaging the values of the five samples (see Figure S1).

In order to characterise community functional composition, and compare the changes in traits due to shifts in species relative abundance or in intraspecific trait values, we calculated four community trait metrics (Figure 1). (a) The sown trait value per plot $=\sum_{i}^{n} x_{i 0} / n$; with $x_{i 0}$ being the trait value of species $i$ in its control monoculture and $n$ the number of species in a plot. We used this as the baseline measure, as it indicates the trait value in control (unfertilised, no fungicide) conditions, for species experiencing intraspecific competition only. We therefore do not measure intraspecific trait changes over time but rather compare control and treatment conditions to infer shifts in response to nitrogen, fungicide application, diversity and community mean trait values. (b) The $\Delta$ abundance shift per plot $=\sum_{i}^{n} p_{i} x_{i 0}-\sum_{i}^{n} x_{i 0} / n$; with $p_{i}$ being the relative abundance of species $i$ in a given plot, and $x_{i 0}$ the trait value of species $i$ in the control monoculture. (c) The $\Delta$ intraspecific shift per plot $=\sum_{i}^{n} x_{i} / n-\sum_{i}^{n} x_{i 0} / n$; with $x_{i}$ being the trait value of the species i measured in a particular plot and $n$ the number of species in a given plot. (d) The overall CWM $=\sum_{i}^{n} p_{i} x_{i}$ ; with $p_{i}$ the relative abundance of the species $i$ and $x_{i}$ the trait value of species $i$ per plot. We did not include monocultures in the analysis, as the $\Delta$ values were equal to 0 , by definition, in a monoculture. Positive $\Delta$ abundance or intraspecific shifts in SLA would indicate that communities are increasingly dominated by fast-growing species (positive $\Delta$ abundance shift) or that species within a community have increased their SLA relative to control (unfertilised, no fungicide, monoculture) conditions (positive intraspecific shift) and negative $\Delta$ shifts in SLA indicate a slower community than expected. LDMC has the opposite pattern: positive $\Delta$ shifts indicate slower communities whereas negative $\Delta$ shifts indicate faster communities, than expected from the sown values.

Two species, Anthriscus sylvestris and Heracleum sphondylium established very slowly in the experiment and were rare in the first years. Because of a lack of plants of these two species, we excluded them completely from the community trait calculations. Seven of our 18 
remaining species did not establish or were present at very low percentage covers in 36 of the 200 plots. The traits of these species could not be sampled ( 44 out of 716 data points). Although this did not influence the abundance shift and CWM calculations, we replaced these values with monoculture data in the intraspecific shift calculations and therefore made the conservative assumption that the intraspecific shift would have been 0 for these species. However, completely excluding these species did not change the intraspecific shift effect, see Table S1.

\section{3 | Analysis}

We tested how our different manipulations, $\mathrm{N}$ fertilisation, fungicide application, sown species richness and sown species composition (mean SLA/LDMC of the sown species) influenced intraspecific and abundance shifts and CWM SLA and LDMC. We then also tested how the sown traits, intraspecific and abundance shifts affected ecosystem functioning. We used a three-step procedure: first, we fitted a set of linear mixed effect models to screen for potential interactions between treatments in effecting trait shifts. In a second step, we fitted a set of structural equation models (SEMs, Grace, 2006) to disentangle the contributions of abundance and intraspecific shifts to CWM traits and in a third step we looked at their effects on ecosystem functioning.

\subsection{1 | Step 1: treatment effects on inter- and intraspecific trait variability}

We fitted four linear mixed models for the two abundance shifts ( $\Delta$ abundance shift in SLA and LDMC) and two intraspecific shifts ( $\Delta$ intraspecific shift in SLA and LDMC). Each model included the effect of $\mathrm{N}$ enrichment, fungicide, sown plant species richness, sown mean traits and all twofold interactions, as fixed effects, and random intercepts for block and species composition (the randomly assembled sets of species). The data were not transformed because the errors were normally distributed and the variance homogenous. We simplified the initial models (backwards model selection) using likelihood-ratio tests to drop fixed terms that did not significantly improve overall model fit (Zuur et al., 2009). Random effects were always kept in the model as they are part of the experimental design. The Imer models were fitted in R using the package LME4 (Bates et al., 2015; R. Core Team, 2019).

\subsection{2 | Step 2: effects of intra- and interspecific trait variation in affecting community weighted mean traits}

We fitted a separate SEM for each trait to explore the role of the treatments in driving intraspecific and abundance shifts and the relative importance of these two shifts in determining the overall CWM traits. Sown SLA and LDMC were not highly correlated $(-0.45)$, but the correlation between the $\Delta$ intraspecific shifts of
SLA and LDMC (-0.69) prevented us from having both traits in one model (see Figure S2). We fitted direct paths from $\mathrm{N}$ enrichment, species richness, fungicide and sown trait values to the $\Delta$ abundance shift and the $\Delta$ intraspecific shift, with the hypothesis that $\mathrm{N}$, richness and fungicide would increase the two $\Delta$ SLA shifts and decrease the two $\triangle$ LDMC shifts. Interactions between all of the experimental treatments are plausible, however, incorporating large numbers of interactions in SEMs is challenging. As there is no theory to predict which interactions should be important (for instance that $\mathrm{N}$ affects intraspecific shifts of slow and fast species differently, but that fungicide has consistent effects across fast and slow species), we used the linear mixed effects models from step 1 to determine which interactions to include in the SEMs. We added paths from interactions between sown SLA and the three other factors to intraspecific shift SLA, to test how the treatment effects depended on the community growth strategy, and a path from an interaction between richness and fungicide to abundance shift SLA, as these interactions were all significant in the LMMs (Table S2). For the LDMC model, we added an interaction between richness and $\mathrm{N}$ on abundance shift LDMC. To assess the relative importance of sown community composition, abundance shifts and intraspecific shifts in determining overall CWM trait values, we then fitted direct paths from the sown trait values, and the two $\Delta \mathrm{s}$, to the CWM trait. The SEMs were fitted using the LAVAAN package (Rosseel, 2012), which uses a global estimation of parameters. It was not possible to include the random effects in this SEM, which might lead to a slightly inflated significance for the species richness main effect (as it should be tested against between compositional variation not between plot variation), however, species richness had no main effects in the SEM, it only had effects in interaction with other variables, so this is not a problem.

\subsection{3 | Step 3: effects of intra- and interspecific trait variation on ecosystem functioning}

The second set of SEMs tested the relative importance of the treatments and aspects of community mean trait values in affecting above- and below-ground biomass. The structure was similar, but we fitted paths to above- and below-ground biomass rather than CWM traits. We added paths from N, fungicide and species richness to above-ground and below-ground biomass, to include additional direct (hypothesised positive) effects of these factors on biomass, not occurring through changes in SLA or in LDMC. Above-ground biomass data were square-root transformed and below-ground biomass data were log-transformed in order to meet model assumptions.

We deliberately chose to fit CWM traits and biomass values in two separate models to more clearly show the factors affecting each of them. We did not want to test for the overall effect of mean traits on biomass because we aim to test the relative importance of intraspecific and abundance shifts in separately determining mean trait values and in affecting biomass production. However, fitting a model with both CWMs and biomass together does not affect the results. 


\section{$3 \mid$ RESULTS}

\section{1 | Trait responses to the experimental treatments}

Community weighted mean values of SLA and LDMC were affected by the manipulated compositional variation (the sown community values) but also by species intraspecific and abundance shifts (Figures $2 \mathrm{~A}$ and $3 \mathrm{~A}$, Tables S3 and S4 and Figures S3 and S4). The intraspecific trait shift was on average positive for SLA (mean $0.61 \pm$ SE 0.21) and $\operatorname{LDMC}(2.46 \pm 1.47)$, while abundance shifts were on average negative for SLA $(-1.30 \pm 0.24)$ and LDMC $(-15.40 \pm 1.68$, see Figures $2 A, G$ and $3 A, E)$. This resulted in a convergence of the communities towards intermediate values of CWM SLA and LDMC by slightly increasing mean trait values in plots sown with low SLA/LDMC species and reducing them in plots sown with high SLA/LDMC species (Figures $2 \mathrm{~F}$ and 3D). For both traits, intraspecific shifts contributed as much to variation in the final CWM traits as abundance shifts. For LDMC the intraspecific shifts even had a similar magnitude of effect on the CWM as sown, compositional variation between the plots (path coefficient of $0.63 \pm 0.05$ for sown LDMC and $0.53 \pm 0.05$ for intraspecific shifts), while for SLA the sown, compositional variation had the same effect as intraspecific and abundance shifts together (path coefficient for sown SLA of $0.98 \pm 0.04$, intraspecific shift $0.44 \pm 0.03$ and abundance shift $0.54 \pm 0.04)$. See further details in supplementary results.

Plant species richness, $\mathrm{N}$ addition and fungicide application, in interaction with sown SLA, all caused intraspecific shifts in SLA (Figure 2A) but had no effect on intraspecific shifts in LDMC (Figure $3 A$ ). Species, on average, increased their SLA compared to monoculture, in plots with low sown SLA (Figure 2B,D). In plots with high sown SLA, species increased their SLA only when $N$ was added (Figure 2B). Fungicide had the opposite effect and SLA was reduced when fungicide was added to plots sown with high SLA species (Figure 2D). Sown diversity also changed the response: in plots with four species, SLA responses were highly variable whereas in plots sown with eight species, SLA increased in plots sown with low SLA species, and declined in plots sown with high SLA species (Figure $2 \mathrm{C}$ ).

Abundance shifts that altered SLA were only affected by sown SLA and not by any other treatments (Figure 2A). Abundance shifts that altered LDMC on the contrary depended on all experimental treatments (Figure 3A): fungicide application led to abundance shifts that reduced mean LDMC (Figure $3 \mathrm{~A}$ ). This indicates that species with a relatively low LDMC dominated in plots where foliar fungal pathogens were removed. Species richness and $\mathrm{N}$ interacted to affect abundance shifts in LDMC: low LDMC species dominated more in eight species plots but $\mathrm{N}$ dampened this effect (Figure 3B).

\subsection{Effects of trait shifts on ecosystem function}

Whereas intraspecific trait shifts explained the same amount of variation in CWM traits as abundance shifts, this did not translate into an effect of intraspecific shifts on ecosystem functioning (Figures 4 and 5, Figures S5 and S6 and Tables S5 and S6). Only abundance shifts affected above- and below-ground biomass. Increased abundance of high SLA species increased above-ground biomass production and decreased below-ground production, indicating contrasting effects of SLA on these two ecosystem functions (Figure 4B,C). Initial compositional variation was also important as a high sown SLA further decreased below-ground biomass, although sown SLA had no effect on above-ground biomass, after taking the abundance shifts into account. Similarly, LDMC shifts only affected functioning through shifts in abundance, but not through intraspecific shifts. Shifts in species abundances towards higher mean LDMC increased below-ground biomass (Figure 5B,C), which agrees with the SLA effect and indicates that plots dominated by slow-growing species had higher root production. High values of sown LDMC also increased below-ground biomass. None of the measures of LDMC affected above-ground biomass and in the LDMC SEM, above-ground biomass was only directly affected by $\mathrm{N}$ enrichment. Species richness had no direct effect on functioning, however, this is probably because we only included data from the four and eight species plots, which means there was very low variation in species richness.

\section{4 | DISCUSSION}

As expected, we found that our experimental treatments, simulating direct and indirect effects of nitrogen enrichment, caused large

FIGURE 2 Effect of nitrogen, fungicide, species richness and sown SLA on community weighted mean SLA through a shift in intraspecific trait values ( $\Delta$ intraspecific shift) or in species abundance ( $\Delta$ abundance shift). $N=120$ plots. (A) Significant output of the structural equation model. Blue arrows show a positive effect, red a negative effect, grey is non-significant (in interactions only). The size of the arrows is proportional to the path coefficient, see Table S3 and Figure S3 for full model description and output including non-significant paths. $R^{2}$ values are the coefficient of determination for each endogenous variable. The effect of nitrogen, fungicide and species richness on the intraspecific shift in SLA depended on the SLA of the initial sown community. These interactions are shown in the SEM using two arrows, which show the effect of N, fungicide and richness at low and high SLA. The interactions are also visualised using partial plots: effect of sown SLA on $\Delta$ intraspecific shift depending on (B) N enrichment, (C) species richness and (D) fungicide. (E) Effect of sown SLA on $\Delta$ abundance shift. (F) Overall effect (direct and indirect) of sown SLA on CWM SLA. (G) Amount of variation in community mean SLA when calculated using sown values, intraspecific shift, abundance shift or CWM values. Figures $b$ to $f$ : The grey line indicates no changes from the sown values. Values above the grey line mean that plants expressed higher SLA in the plots than in the control monoculture (b-d) or species with high SLA increased in abundance at the cost of species with low SLA (e), values below the grey line indicate the opposite. Figures $b$ to e: $x$-axis units are back-transformed values, $y$-axis are back-transformed residuals of the target explanatory variables on the remaining explanatory variables 
changes in functional composition, in terms of the CWM values of SLA and LDMC. These trait responses were driven by both intraspecific trait changes and shifts in species abundances, indicating that intra- and interspecific changes were of similar importance in determining changes in response trait composition. However, intraspecific trait changes and abundance shifts tended to be opposing,

(A)

$p$ value $1.000 ; \mathrm{X}^{2}$ 7.430; $d f$ 28; RMSEA 0.000

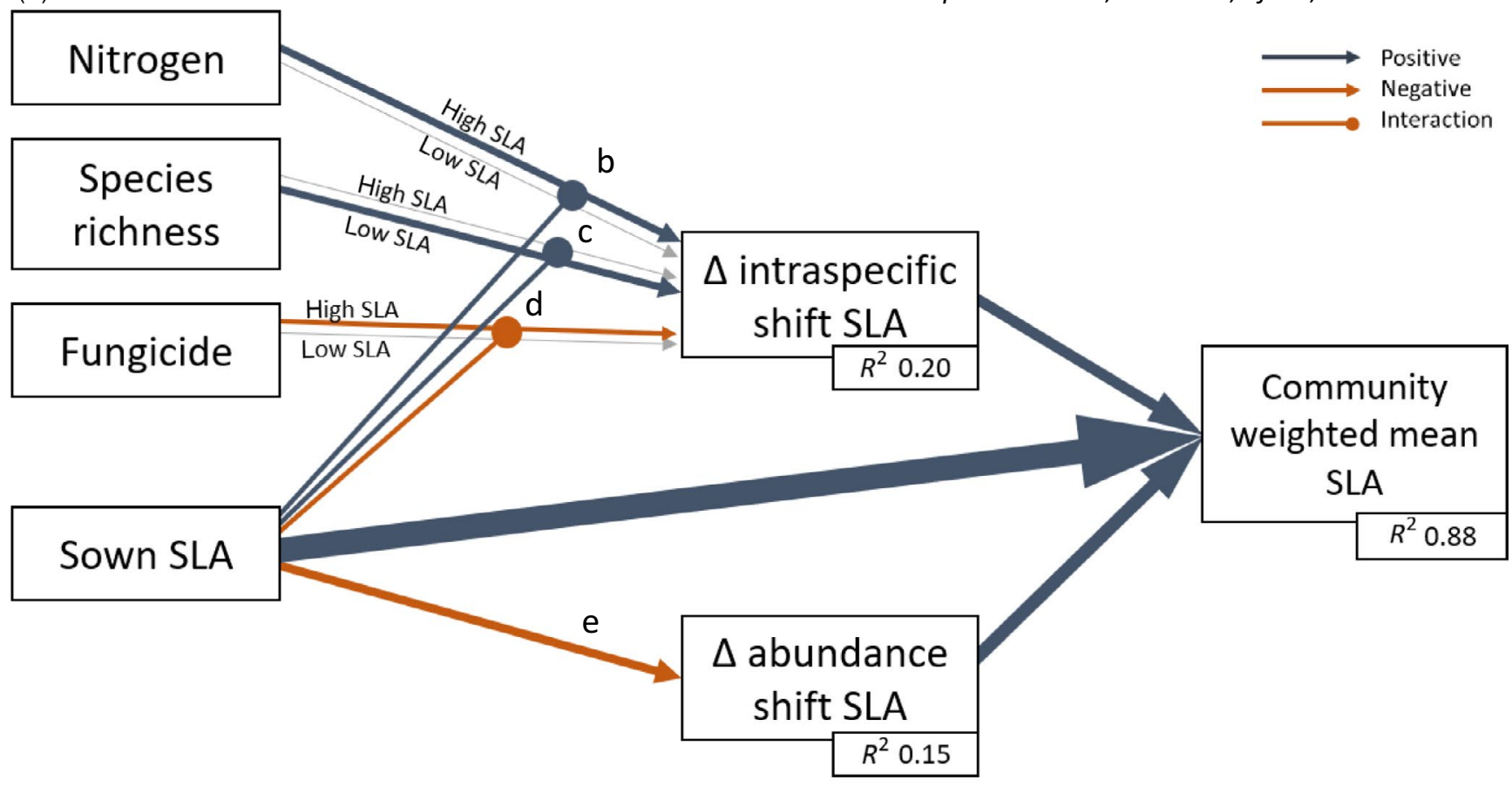

(B) Treatment

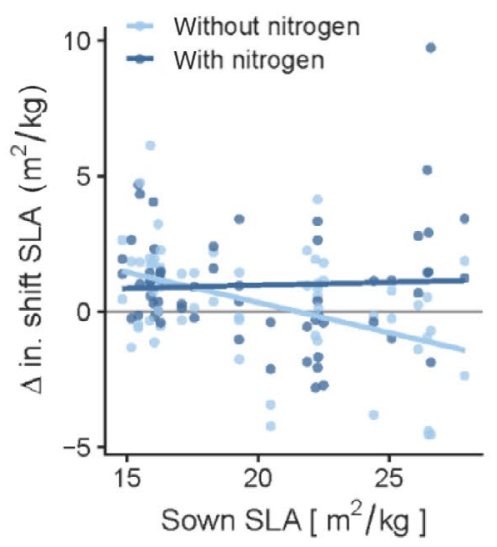

(E)

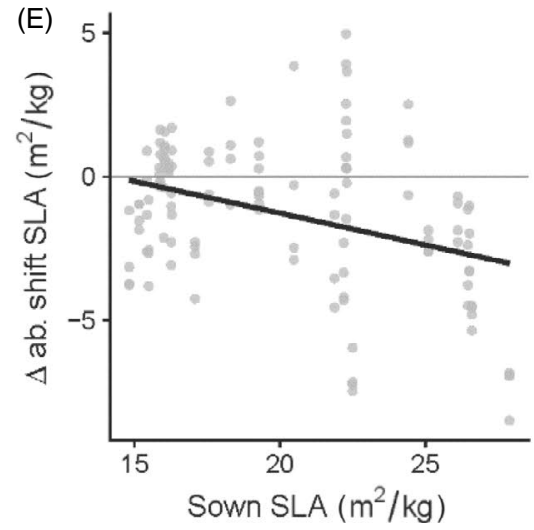

(C) Species richness

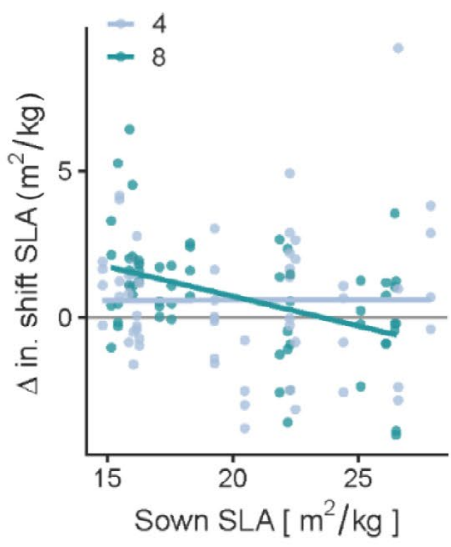

(F)

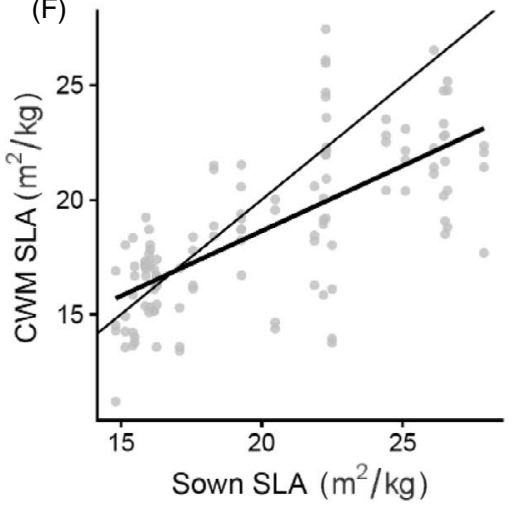

(D) Treatment
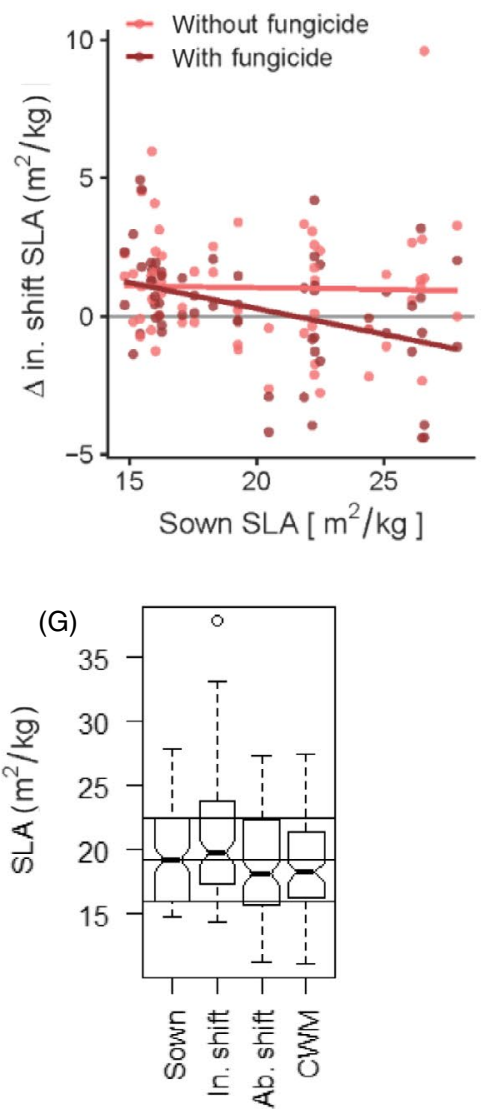

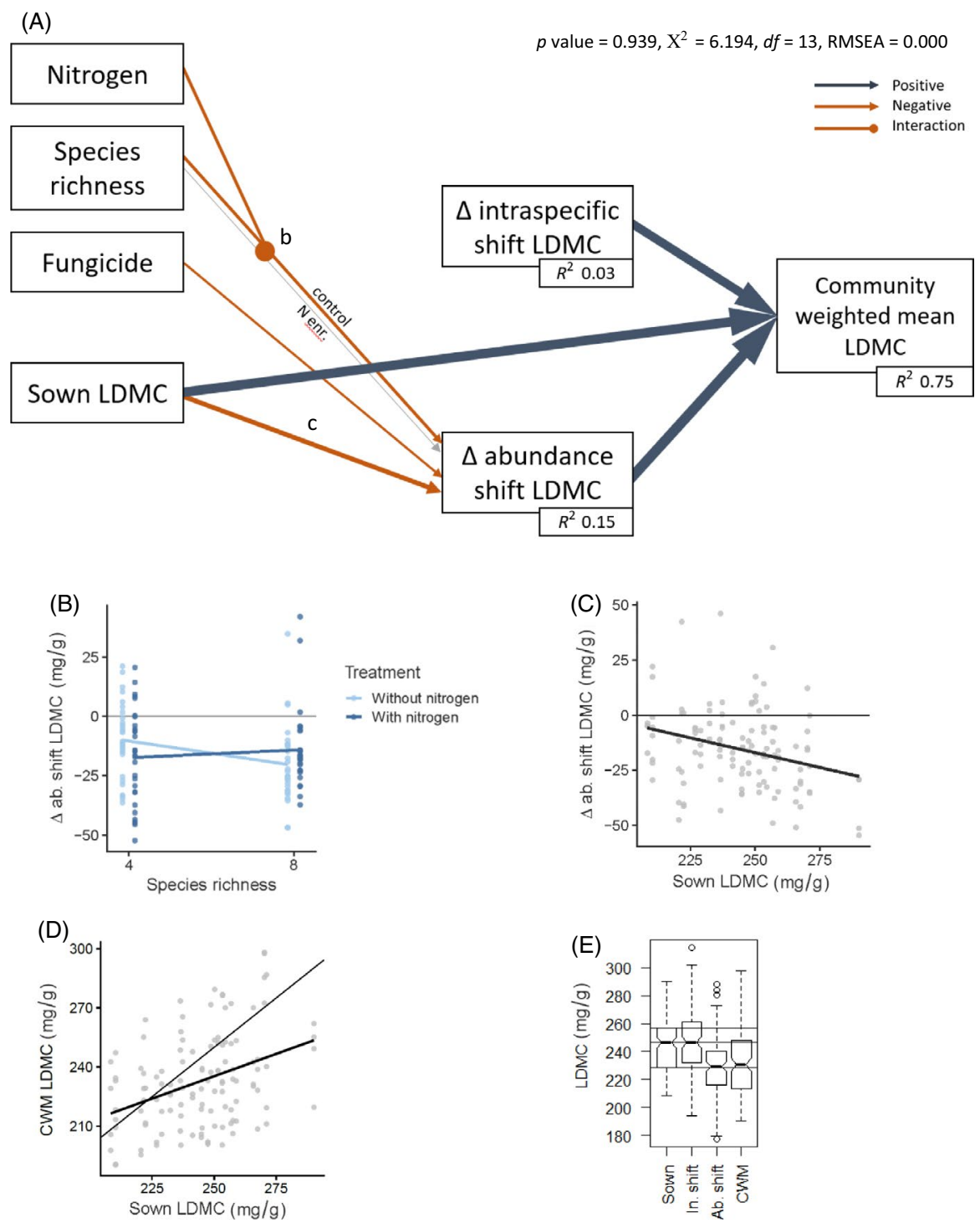
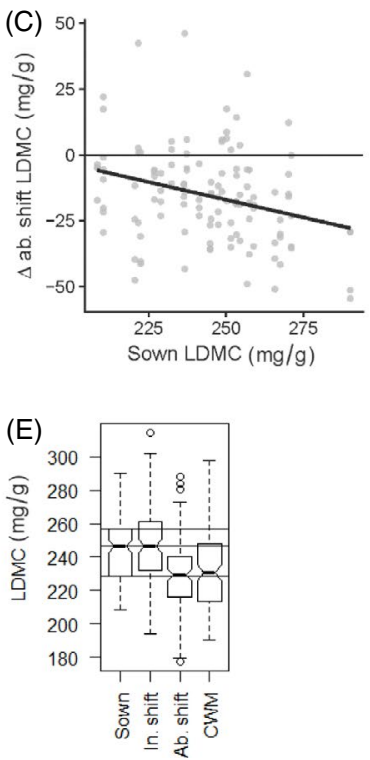

FIGURE 3 Effect of nitrogen, fungicide, species richness and sown mean traits on community weighted mean leaf dry matter content (LDMC) through a shift in intraspecific trait values ( $\Delta$ intraspecific shift) or in species abundance ( $\Delta$ abundance shift). $N=120$ plots.

(A) Significant output of the structural equation model. Blue arrows show a positive effect, red a negative effect, grey is non-significant (in interactions only). The size of the arrows is proportional to the path coefficient. See Table S4 and Figure S4 for full model description and output including non-significant paths. $R^{2}$ values are the coefficient of determination for each endogenous variable. Partial plots visualising (B) the interactive effect of nitrogen and species richness on $\Delta$ abundance shift, and (C) the effect of sown LDMC on $\Delta$ abundance shift. (D) Overall effect (direct and indirect) of sown LDMC on CWM LDMC. The grey line indicates no changes from the sown values. (E) Amount of variation in community mean LDMC when calculated using sown values, intraspecific shift, abundance shift or CWM values. Figures $b$ and c: $x$-axis units are back-transformed values, $y$-axis are back-transformed residuals of the target explanatory variables on the remaining explanatory variables indicating that trait responses may vary between versus within species. Furthermore, and in contrast to our expectations, despite the large intraspecific trait changes it was only the abundance shifts that affected functioning. This result confirms that interspecific trait variation is an important driver of functioning (Roscher et al., 2018) but shows that intraspecific trait changes may not cause the same changes, which cautions about using intraspecific variation in effect traits to predict ecosystem functioning. Taken together, these contrasting responses and effects for intra- and interspecific trait variation show that response-effect correlations that occur between species may break down within species.

\section{1 | Intraspecific trait shifts have large effects on overall functional composition}

Our results showed that changes in functional composition due to abundance and intraspecific shifts were of similar importance in explaining overall CWM trait measures. As expected, the large gradient in initial (sown) trait composition was the largest driver of the observed variation in CWM traits, however, abundance and intraspecific trait shifts also had large effects and were even of similar importance in driving variation in community mean LDMC. The importance of intraspecific variation in SLA is in agreement with an increasing volume of literature (Albert et al., 2011; Carmona et al., 2016; Lepš et al., 2011; Violle et al., 2012), and our results also highlight substantial variation in LDMC, which is often considered less plastic than SLA (Garnier, Shipley, et al., 2001). Previous studies have shown that intraspecific variation becomes more important at smaller scales, with more homogenous environmental conditions, where interspecific trait variation is lower (Cordlandwehr et al., 2013; Petruzzellis et al., 2017). We experimentally created a large gradient in mean leaf traits, similar to the variation between extensively and intensively managed grasslands (Breitschwerdt et al., 2018), and even relative to this large initial variation in interspecific trait composition, intraspecific trait shifts explained a substantial amount of the total functional variation between communities. In addition, applying $\mathrm{N}$ and fungicide treatments meant that there was substantial 
FIGURE 4 Effect of nitrogen, fungicide, species richness and sown SLA on aboveground and below-ground biomass.

Effects can be direct or through a shift in species abundances ( $\Delta$ abundance shift) or intraspecific trait values ( $\Delta$ intraspecific shift). $N=120$ plots. (A) Significant output of the structural equation model. Blue arrows show a positive effect, red a negative effect. The size of the arrows is proportional to the path coefficient, see Table S5 and Figure S5 for full model description and output. The light-coloured arrows are described in Figure 2. $R^{2}$ values are the coefficient of determination for each endogenous variable. (B) Effect of $\Delta$ abundance shift SLA on above-ground biomass and (C) on below-ground biomass. Figures $b$ and $c$ : The grey line indicates no changes from the sown values. $x$-axis units are back-transformed values, $y$-axis are back-transformed residuals of the target explanatory variables on the remaining explanatory variables
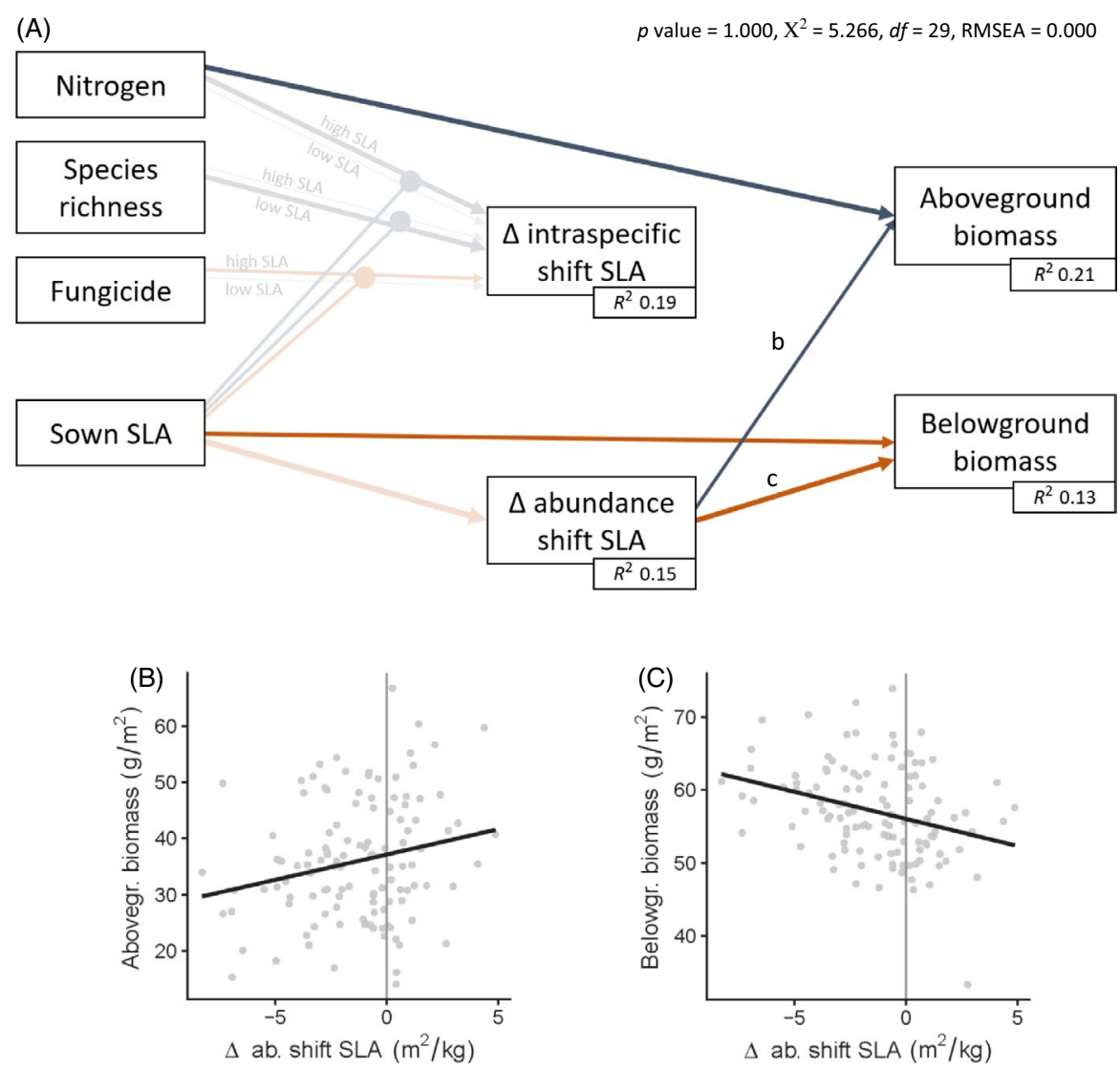

variation in resources and enemy pressure between plots. This large contribution of intraspecific variation to overall community mean traits therefore challenges the idea that within species trait shifts only affect response trait composition when environmental conditions and species are similar.

The abundance and intraspecific shifts caused large, and opposing, changes in response trait composition relative to the originally sown communities. Shifts in species abundances decreased both mean SLA and LDMC across the whole field, which, in our case (Figure S7), shows that slow-growing herbs (low SLA, low LDMC) dominated the experimental communities. In contrast, intraspecific trait shifts increased SLA in most communities. Freschet et al. (2015) hypothesised that acquisitive (fast) species should be more plastic than conservative (slow) ones, however, we find that slow dominated communities also responded strongly and could shift their SLA values substantially. Intraspecific shifts towards higher SLA in mixed communities could be driven by higher light competition compared to monocultures (Lipowsky et al., 2015). However, the intraspecific shifts in SLA were not consistent across plots and were modulated by $\mathrm{N}$ enrichment, fungal pathogen presence and species richness, see below. Opposing intraspecific and abundance shifts and opposing trait shifts in fast and slow species, led to an overall convergence in CWM SLA towards intermediate values, perhaps reflecting the fairly fertile but water limited conditions on our field site. These results show that large intraspecific trait shifts can be decoupled from trait shifts driven by abundance changes. This could be due to correlations between functional traits breaking down at the intraspecific scale (Laughlin et al., 2017).
Low SLA species might show a higher tolerance to dry conditions compared to high SLA species (McDowell et al., 2008; Poorter et al., 2009), partly because they have particular root traits (leading to higher root production, Figure 4A) and might therefore be favoured on our site. However, at the same time light competition in mixed communities favours high SLA values (Lipowsky et al., 2015). If SLA and root traits are decoupled at the intraspecific level (Bergmann et al., 2020), then individuals might increase their SLA in response to shading (leading to positive intraspecific shifts), while at the same time low SLA species are favoured because they are better at competing for soil resources, leading to opposing intra- and interspecific trait shifts. Kichenin et al. (2013) showed that a correlation between SLA and leaf pubescence at the interspecific level broke down within species, so that at high elevation species tended to produce lower SLA leaves to cope with water scarcity but at the same time high SLA species increased in abundance because their pubescent leaves had better water retention capacity. Contrasting intraspecific and abundance shifts show that within and between species trait variation may respond to different aspects of the environment, suggesting that response traits could differ within and between species.

\subsection{The environmental conditions causing trait shifts}

Manipulating environmental conditions changed community SLA through intraspecific shifts, and LDMC through abundance shifts. 
(A)

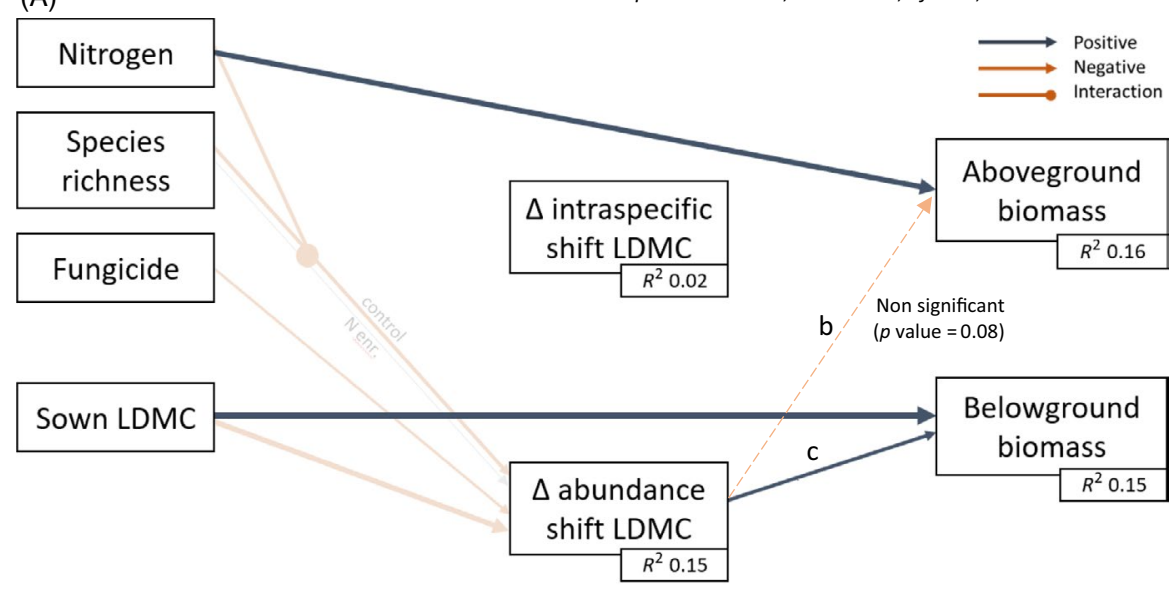

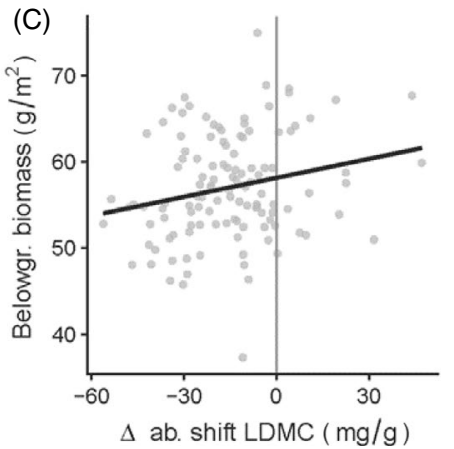

FIGURE 5 Effect of nitrogen, fungicide, species richness and sown leaf dry matter content (LDMC) on aboveground and below-ground biomass. Effects can be direct or through a shift in species abundances ( $\Delta$ abundance shift) or intraspecific trait values ( $\Delta$ intraspecific shift). $N=120$ plots. (A) Significant output of the structural equation model. Blue arrows show a positive effect, red a negative effect. The size of the arrows is proportional to the path coefficient, see Table S6 and Figure S6 for full model description and output. The light-coloured arrows are described in the Figure 3. $R^{2}$ values are the coefficient of determination for each endogenous variable. (B) Effect of $\Delta$ abundance shift LDMC on above-ground biomass and (C) on below-ground biomass. Although only marginally significant, we added in Figure a the path between $\Delta$ abundance shift and above-ground biomass, and Figure $b$, for symmetry with Figure 4. Figures $b$ and c: The grey line indicates no changes from the sown values. $x$-axis units are back-transformed values, $y$-axis are back-transformed residuals of the target explanatory variables on the remaining explanatory variables
These opposing patterns could be due to lower correlations between leaf traits under the different treatments. Laliberté et al., (2012), showed that an increase in community SLA following nutrient enrichment was linked to a decrease in leaf thickness, therefore leading to higher SLA without changing LDMC values. The different ways in which environmental conditions affect community SLA and LDMC could therefore lead to a local decoupling of these two functional traits (Anderegg et al., 2018; Laughlin et al., 2017; Messier et al., 2017). These results further emphasise that trait correlations can break down at certain scales.

Exclusion of fungal pathogens affected intraspecific shifts in SLA. In communities sprayed with fungicide, SLA values shifted towards intermediate values, due to an increase in SLA in slow communities and a decrease in SLA in fast communities. The intraspecific shifts reflected the change in SLA associated with a shift from intra- to interspecific competition. Interspecific competition could lead to either trait divergence, when traits are linked to niche differences, or trait convergence, when they are linked to competitive ability differences (Mayfield \& Levine, 2010), and previous studies have shown that SLA is linked to competitive ability differences, rather than niche differences (Kraft et al., 2015). The presence of fungal pathogens can reduce competitive interactions between plants (Chesson, 2000; Mordecai, 2011) and removing pathogens might therefore have increased interspecific competition in our communities and led to convergence in SLA.

Fungicide spraying increased the abundance of low LDMC species. This result is in line with the growth-defence trade-off
(Heckman et al., 2019), which would predict that fungicide favoured the establishment of fast-growing species (low LDMC) because their energy was invested more in growth than in defence and they thus disproportionately benefitted from pathogen release. We may have observed this abundance shift in LDMC, not in SLA, because LDMC reflects structural components of the leaves that contribute to physical defence against herbivores and pathogens (Descombes et al., 2017; Ibanez et al., 2013). Fungicide therefore decreased both SLA and LDMC but due to intraspecific shifts and abundance shifts respectively.

$\mathrm{N}$ addition led to intraspecific shifts in SLA but did not favour high SLA species in general. $\mathrm{N}$ enrichment directly increased aboveground biomass, showing that productivity is $\mathrm{N}$ limited at our site, however, it did not increase the abundance of high SLA species, contrary to our expectations (Laliberté et al., 2012; Lavorel \& Grigulis, 2012). N enrichment may not have favoured fast, high SLA species, because these remained limited by water, or other nutrients, and therefore SLA was not the key trait determining response to $\mathrm{N}$ alone (Firn et al., 2019; Jung et al., 2014; Poorter et al., 2009; Rosbakh et al., 2015). However, $N$ enrichment did cause intraspecific trait shifts and affected the degree of trait convergence between communities. $\mathrm{N}$ only increased SLA in fast-growing communities, while in slow-growing communities SLA increased regardless of whether communities were fertilised or not. $\mathrm{N}$ addition therefore reduced the convergence in SLA between communities and led to general increases in SLA, as expected. This suggests that fast species reduced 
their SLA when growing in mixtures compared to monocultures, possibly due to increased water or nutrient competition (Poorter et al., 2009), but that $\mathrm{N}$ enrichment dampened this effect.

We found that trait convergence occurred only in eight species communities, not in plots with four species. Lipowsky et al. (2015) also found greater intraspecific shifts in SLA at higher species richness. The greater convergence at higher species richness could have been caused by a stronger interspecific competition with increasing diversity. It could also have been due to a greater trait variation and therefore more opportunities for trait shifts in eight species communities. This would be a type of sampling effect, where eight species communities are more likely to contain species with high genetic variation in traits or with high trait plasticity. The greater convergence in SLA in species rich communities supports the idea that diverse communities are better able to shift their traits to cope with environmental variation (Vogel et al., 2019).

Intraspecific shifts in LDMC were also large: they contributed as much to variation in community mean traits as compositional differences, but we could not explain them. Intraspecific shifts in LDMC could have been driven by variation in microclimatic conditions, for example, water availability, between plots (Jung et al., 2014) or by random processes leading to differential establishment of genotypes in the plots. However, it seems unlikely that genetic variation alone could explain such large intraspecific variation, and speciesspecific responses to unmeasured environmental variation across the plots might be a more plausible explanation (Lajoie \& Vellend, 2018; Siefert et al., 2015).

\subsection{Effect on biomass}

Although intraspecific shifts in SLA and LDMC had large effects on response trait composition (the CWMs), this did not translate into an effect on above- or below-ground biomass production. This result runs counter to the study by Liancourt et al. (2015) which showed that plastic shifts in SLA affected biomass production. However, that study looked at changes in biomass production for individual species under different treatments, which makes it difficult to compare with our measure of overall community biomass production. However our results support those of Roscher et al. (2018) who showed no significant difference in model fits when calculating the effect of CWM traits on biomass using traits measured in monocultures or in mixtures. Intraspecific trait shifts may not have affected functioning because variation in leaf traits is not linked to variation in resource use within species (Anderegg et al., 2018; Messier et al., 2017). The leaf economics spectrum results from a trade-off between high photosynthetic rates in leaves with a large area per unit of invested mass, (high SLA and low LDMC; the acquisitive strategy) versus a long leaf life span and thicker leaves (low SLA and high LDMC; the conservative strategy, Wright et al., 2004). Funk and Cornwell (2013) showed that the link between leaf traits and resource use strategies depends on the amount of variation in leaf life span within a community, meaning the relationship would break down at a small scale. We find that intraspecific shifts in SLA in response to the experimental treatments are broadly in line with expectations (although the responses are more complex than hypothesised), however, these responses seem to be decoupled from the effects of intraspecific trait changes on ecosystem functioning. We therefore show that even when large, intraspecific trait variation is not necessarily important for ecosystem functioning and that response-effect trait correlations are different within versus between species.

Root biomass production increased in communities dominated by slow species. Communities sown with low SLA and high LDMC species, and those in which low SLA and high LDMC species increased their abundance, produced most root biomass. The effect of SLA on root biomass production is rarely assessed (Bergmann et al., 2017; Mommer \& Weemstra, 2012) but we observe that slowgrowing species invested more in roots than fast-growing ones. Plants adapted to resource poor environments would be expected to invest more resources below-ground, as this would give them an advantage under dry or low nutrient conditions (Bergmann et al., 2020; Freschet et al., 2015). In addition, the joint effects of SLA and LDMC on root production indicate that it is slow-growing grasses (low SLA and high LDMC) that had highest root biomass (Gastine et al., 2003; Ravenek et al., 2014). Therefore, the overall reduction in community SLA and LDMC due to abundance shifts had contrasting effects on below-ground biomass production.

Above-ground biomass production was altered by changes in SLA but shifts in abundance and compositional variation had opposing effects. Where plots became dominated by fast (higher SLA) species, above-ground biomass production increased. However, sown community SLA had a negative indirect effect on biomass (by reducing SLA through abundance shifts) and we could see some evidence for a negative direct effect (marginally significant, see Table S5). This means that sown SLA decreased above-ground biomass production, which was the opposite of our expectation (Lavorel \& Grigulis, 2012). The effect is likely due to the better establishment of slow species at the beginning of the experiment. In the first year of the experiment, species suffered drought stress due to large amounts of bare ground ( $\mathrm{N}$. A. Pichon, pers. obs.). Slow-growing, low SLA species may therefore have established better in the first year because of their higher investment in root biomass. This initial advantage for slow species means that plots with only fast species present (high sown SLA) still produce less biomass overall. However, the communities that were increasingly dominated by faster growing species, that is, in which SLA increased due to abundance shifts, produced higher above-ground biomass. These contradictory results draw attention to the importance of initial establishment conditions (as in Mahaut et al., 2020 for instance) and suggest that relationships between effect traits and functions may change during community reassembly (Galland et al., 2019).

\section{5 | CONCLUSIONS}

Intraspecific changes in resource economics traits had large effects on overall functional composition, which were similar in magnitude 
to abundance changes, showing that measuring traits in situ is important to accurately quantify functional composition and to predict responses to global change. Intraspecific trait shifts tended to lead to convergence in community mean traits between diverse communities, however, the degree of convergence depended on resource levels, plant species diversity and enemy abundance. Intra- and interspecific shifts were opposing, suggesting that trait correlations may break down at certain scales. Although large, intraspecific trait shifts did not translate into an effect on above- or below-ground biomass production. Intraspecific trait variation may therefore have different effects on function compared to interspecific trait differences, suggesting that incorporating intraspecific trait variation into measures of effect trait composition may not improve predictions of functioning. Our results highlight the importance of a better understanding of how response and effect traits correlate at different scales and suggest that inter- and intraspecific trait variation may have different consequences for ecosystem functioning.

\section{ACKNOWLEDGEMENTS}

We thank Hugo Vincent, Mervi Laitinen and Marlise Zimmermann, the technicians working with us on the PaNDiv Experiment, the large team of helpers on the field and in the laboratory, as well as two anonymous reviewers and the editor for their valuable input. This study was supported by funding of the Swiss National Science Foundation (31003A_160212).

\section{CONFLICT OF INTEREST}

The authors declare that they have no conflict of interest.

\section{AUTHORS' CONTRIBUTIONS}

N.A.P., S.L.C. and E.A. designed and set up the PaNDiv Experiment; N.A.P. and S.L.C. collected the data; N.A.P. analysed the data and wrote the first manuscript with substantial input from E.A. and S.L.C. All authors contributed to revisions of the manuscript. E.A. is an Associate Editor of Journal of Ecology, but took no part in the peer review and decision-making processes for this paper.

\section{PEER REVIEW}

The peer review history for this article is available at https://publo ns.com/publon/10.1111/1365-2745.13827.

\section{DATA AVAILABILITY STATEMENT}

The relevant data are archived on Dryad Digital Repository https:// doi.org/10.5061/dryad.7sqv9s4t9 (Allan et al., 2021).

\section{ORCID}

Noémie A. Pichon (D) https://orcid.org/0000-0003-2972-1912 Seraina L. Cappelli (D) https://orcid.org/0000-0002-8141-404X Eric Allan (D) https://orcid.org/0000-0001-9641-9436

\section{REFERENCES}

Albert, C. H. (2015). Intraspecific trait variability matters. Journal of Vegetation Science, 26(1), 7-8. https://doi.org/10.1111/jvs.12240
Albert, C.H., Grassein, F., Schurr, F.M., Vieilledent, G., \& Violle, C. (2011). When and how should intraspecific variability be considered in trait-based plant ecology? Perspectives in Plant Ecology, Evolution and Systematics, 13(3), 217-225. https://doi.org/10.1016/j.ppees.2011.04.003

Allan, E., Manning, P., Alt, F., Binkenstein, J., Blaser, S., Blüthgen, N., Böhm, S., Grassein, F., Hölzel, N., Klaus, V. H., Kleinebecker, T., Morris, E. K., Oelmann, Y., Prati, D., Renner, S. C., Rillig, M. C., Schaefer, M., Schloter, M., Schmitt, B., ... Fischer, M. (2015). Land use intensification alters ecosystem multifunctionality via loss of biodiversity and changes to functional composition. Ecology Letters, 18(8), 834-843. https://doi.org/10.1111/ele.12469

Allan, E., Cappelli, S. L., \& Pichon, N. A. (2021). Data from: Intraspecific trait changes have large impacts on community functional composition but do not affect ecosystem function. Dryad Digital Respiratory, https://doi.org/10.5061/dryad.7sqv9s4t9

Anderegg, L. D. L., Berner, L. T., Badgley, G., Sethi, M. L., Law, B. E., \& HilleRisLambers, J. (2018). Within-species patterns challenge our understanding of the leaf economics spectrum. Ecology Letters, 21(5), 734-744. https://doi.org/10.1111/ele.12945

Bates, D., Mächler, M., Bolker, B., \& Walker, S. (2015). Fitting linear mixed-effects models using Ime4. Journal of Statistical Software, 67(1). https://doi.org/10.18637/jss.v067.i01

Battye, W., Aneja, V. P., \& Schlesinger, W. H. (2017). Is nitrogen the next carbon? Earth's Future, 5(9), 894-904. https://doi. org/10.1002/2017EF000592

Bergmann, J., Ryo, M., Prati, D., Hempel, S., \& Rillig, M. C. (2017). Root traits are more than analogues of leaf traits: The case for diaspore mass. New Phytologist, 216(4), 1130-1139. https://doi.org/10.1111/nph.14748

Bergmann, J., Weigelt, A., van der Plas, F., Laughlin, D. C., Kuyper, T. W., Guerrero-Ramirez, N., Valverde-Barrantes, O. J., Bruelheide, H., Freschet, G. T., Iversen, C. M., Kattge, J., McCormack, M. L., Meier, I. C., Rillig, M. C., Roumet, C., Semchenko, M., Sweeney, C. J., van Ruijven, J., York, L. M., \& Mommer, L. (2020). The fungal collaboration gradient dominates the root economics space in plants. Science Advances, 6(27). https://doi.org/10.1126/sciadv.aba3756

Blumenthal, D., Mitchell, C. E., Pyšek, P., \& Jarošík, V. (2009). Synergy between pathogen release and resource availability in plant invasion. Proceedings of the National Academy of Sciences of the United States of America, 106(19), 7899-7904. https://doi.org/10.1073/ pnas.0812607106

Bobbink, R., Hicks, K., Galloway, J., Spranger, T., Alkemade, R., Ashmore, M., Bustamante, M., Cinderby, S., Davidson, E., Dentener, F., Emmett, B., Erisman, J.-W., Fenn, M., Gilliam, F., Nordin, A., Pardo, L., \& De Vries, W. (2010). Global assessment of nitrogen deposition effects on terrestrial plant diversity: A synthesis. Ecological Applications, 20(1), 30-59. https://doi.org/10.1890/08-1140.1

Breitschwerdt, E., Jandt, U., \& Bruelheide, H. (2018). Using co-occurrence information and trait composition to understand individual plant performance in grassland communities. Scientific Reports, 8(1), 9076. https://doi.org/10.1038/s41598-018-27017-9

Cappelli, S. L., Pichon, N. A., Kempel, A., \& Allan, E. (2020). Sick plants in grassland communities: A growth-defense trade-off is the main driver of fungal pathogen abundance. Ecology Letters, 23(9), 13491359. https://doi.org/10.1111/ele.13537

Carmona, C. P., de Bello, F., Mason, N. W. H., \& Lepš, J. (2016). Traits without borders: Integrating functional diversity across scales. Trends in Ecology \& Evolution, 31(5), 382-394. https://doi.org/10.1016/j. tree.2016.02.003

Chesson, P. (2000). Mechanisms of maintenance of species diversity. Annual Review of Ecology and Systematics, 31(1), 343-366. https:// doi.org/10.1146/annurev.ecolsys.31.1.343

Cordlandwehr, V., Meredith, R. L., Ozinga, W. A., Bekker, R. M., Groenendael, J. M., \& Bakker, J. P. (2013). Do plant traits retrieved from a database accurately predict on-site measurements? Journal of Ecology, 101(3), 662-670. https://doi.org/10.1111/1365-2745.12091 
de Vries, F. T., Manning, P., Tallowin, J. R. B., Mortimer, S. R., Pilgrim, E. S., Harrison, K. A., Hobbs, P. J., Quirk, H., Shipley, B., Cornelissen, J. H. C., Kattge, J., \& Bardgett, R. D. (2012). Abiotic drivers and plant traits explain landscape-scale patterns in soil microbial communities. Ecology Letters, 15(11), 1230-1239. https://doi. org/10.1111/j.1461-0248.2012.01844.x

Delarze, R., Gonseth, Y., Eggenberg, S., \& Vust, M. (2015). Lebensräume der Schweiz (3rd ed.). Hep Verlag AG.

Descombes, P., Marchon, J., Pradervand, J.-N., Bilat, J., Guisan, A., Rasmann, S., \& Pellissier, L. (2017). Community-level plant palatability increases with elevation as insect herbivore abundance declines. Journal of Ecology, 105(1), 142-151. https://doi. org/10.1111/1365-2745.12664

Díaz, S., Kattge, J., Cornelissen, J. H. C., Wright, I. J., Lavorel, S., Dray, S., Reu, B., Kleyer, M., Wirth, C., Colin Prentice, I., Garnier, E., Bönisch, G., Westoby, M., Poorter, H., Reich, P. B., Moles, A. T., Dickie, J., Gillison, A. N., Zanne, A. E., ... Gorné, L. D. (2016). The global spectrum of plant form and function. Nature, 529(7585), 167-171. https://doi.org/10.1038/nature16489

Díaz, S., Lavorel, S., de Bello, F., Quetier, F., Grigulis, K., \& Robson, T. M. (2007). Incorporating plant functional diversity effects in ecosystem service assessments. Proceedings of the National Academy of Sciences of the United States of America, 104(52), 20684-20689. https://doi.org/10.1073/pnas.0704716104

Dordas, C. (2008). Role of nutrients in controlling plant diseases in sustainable agriculture. A review. Agronomy for Sustainable Development, 28(1), 33-46. https://doi.org/10.1051/agro:2007051

Firn, J., McGree, J. M., Harvey, E., Flores-Moreno, H., Schütz, M., Buckley, Y. M., Borer, E. T., Seabloom, E. W., La Pierre, K. J., MacDougall, A. M., Prober, S. M., Stevens, C. J., Sullivan, L. L., Porter, E., Ladouceur, E., Allen, C., Moromizato, K. H., Morgan, J. W., Harpole, W. S., ... Risch, A. C. (2019). Leaf nutrients, not specific leaf area, are consistent indicators of elevated nutrient inputs. Nature Ecology \& Evolution, 3(3), 400-406. https://doi. org/10.1038/s41559-018-0790-1

Freschet, G. T., Swart, E. M., \& Cornelissen, J. H. C. (2015). Integrated plant phenotypic responses to contrasting above- and belowground resources: Key roles of specific leaf area and root mass fraction. New Phytologist, 206(4), 1247-1260. https://doi.org/10.1111/ nph.13352

Funk, J. L., \& Cornwell, W. K. (2013). Leaf traits within communities: Context may affect the mapping of traits to function. Ecology, 94(9), 1893-1897. https://doi.org/10.1890/12-1602.1

Galland, T., Adeux, G., Dvořáková, H., E-Vojtkó, A., Orbán, I., Lussu, M., Puy, J., Blažek, P., Lanta, V., Lepš, J., Bello, F., Pérez Carmona, C., Valencia, E., \& Götzenberger, L. (2019). Colonization resistance and establishment success along gradients of functional and phylogenetic diversity in experimental plant communities. Journal of Ecology, 107(5), 2090-2104. https://doi. org/10.1111/1365-2745.13246

Garnier, E., Laurent, G., Bellmann, A., Debain, S., Berthelier, P., Ducout, B., Roumet, C., \& Navas, M.-L. (2001). Consistency of species ranking based on functional leaf traits. New Phytologist, 152(1), 69-83. https://doi.org/10.1046/j.0028-646x.2001.00239.x

Garnier, E., Shipley, B., Roumet, C., \& Laurent, G. (2001). A standardized protocol for the determination of specific leaf area and leaf dry matter content. Functional Ecology, 15(5), 688-695. https://doi. org/10.1046/j.0269-8463.2001.00563.x

Gastine, A., Scherer-Lorenzen, M., \& Leadley, P. W. (2003). No consistent effects of plant diversity on root biomass, soil biota and soil abiotic conditions in temperate grassland communities. Applied Soil Ecology, 24(1), 101-111. https://doi.org/10.1016/S0929-1393(02)00137-3

Geber, M. A., \& Griffen, L. R. (2003). Inheritance and natural selection on functional traits. International Journal of Plant Sciences, 164(S3), S21-S42. https://doi.org/10.1086/368233
Grace, J. B. (2006). Structural equation modeling and natural systems. Cambridge University Press. https://doi.org/10.1017/CBO97 80511617799

Heckman, R. W., Halliday, F. W., \& Mitchell, C. E. (2019). A growthdefense trade-off is general across native and exotic grasses. Oecologia, 191(3), 609-620. https://doi.org/10.1007/s00442-01904507-9

Henn, J. J., Buzzard, V., Enquist, B. J., Halbritter, A. H., Klanderud, K., Maitner, B. S., Michaletz, S. T., Pötsch, C., Seltzer, L., Telford, R. J., Yang, Y., Zhang, L., \& Vandvik, V. (2018). Intraspecific trait variation and phenotypic plasticity mediate alpine plant species response to climate change. Frontiers in Plant Science, 9, 1548. https://doi. org/10.3389/fpls.2018.01548

Ibanez, S., Lavorel, S., Puijalon, S., \& Moretti, M. (2013). Herbivory mediated by coupling between biomechanical traits of plants and grasshoppers. Functional Ecology, 27(2), 479-489. https://doi. org/10.1111/1365-2435.12058

Jung, V., Albert, C. H., Violle, C., Kunstler, G., Loucougaray, G., \& Spiegelberger, T. (2014). Intraspecific trait variability mediates the response of subalpine grassland communities to extreme drought events. Journal of Ecology, 102(1), 45-53. https://doi. org/10.1111/1365-2745.12177

Jung, V., Violle, C., Mondy, C., Hoffmann, L., \& Muller, S. (2010). Intraspecific variability and trait-based community assembly: Intraspecific variability and community assembly. Journal of Ecology, 98(5), 1134-1140. https://doi. org/10.1111/j.1365-2745.2010.01687.x

Kichenin, E., Wardle, D. A., Peltzer, D. A., Morse, C. W., \& Freschet, G. T. (2013). Contrasting effects of plant inter- and intraspecific variation on community-level trait measures along an environmental gradient. Functional Ecology, 27(5), 1254-1261. https://doi. org/10.1111/1365-2435.12116

Kraft, N. J. B., Godoy, O., \& Levine, J. M. (2015). Plant functional traits and the multidimensional nature of species coexistence. Proceedings of the National Academy of Sciences of the United States of America, 112(3), 797-802. https://doi.org/10.1073/pnas.1413650112

Lajoie, G., \& Vellend, M. (2018). Characterizing the contribution of plasticity and genetic differentiation to community-level trait responses to environmental change. Ecology and Evolution, 8(8), 3895-3907. https://doi.org/10.1002/ece3.3947

Laliberté, E., Shipley, B., Norton, D. A., \& Scott, D. (2012). Which plant traits determine abundance under long-term shifts in soil resource availability and grazing intensity? Plant traits and species abundance. Journal of Ecology, 100(3), 662-677. https://doi. org/10.1111/j.1365-2745.2011.01947.x

Laughlin, D. C., Lusk, C. H., Bellingham, P. J., Burslem, D. F. R. P., Simpson, A. H., \& Kramer-Walter, K. R. (2017). Intraspecific trait variation can weaken interspecific trait correlations when assessing the wholeplant economic spectrum. Ecology and Evolution, 7(21), 8936-8949. https://doi.org/10.1002/ece3.3447

Lavorel, S., \& Garnier, E. (2002). Predicting changes in community composition and ecosystem functioning from plant traits: Revisiting the Holy Grail. Functional Ecology, 16(5), 545-556. https://doi. org/10.1046/j.1365-2435.2002.00664.x

Lavorel, S., \& Grigulis, K. (2012). How fundamental plant functional trait relationships scale-up to trade-offs and synergies in ecosystem services: Plant traits scale to ecosystem services trade-offs. Journal of Ecology, 100(1), 128-140. https://doi. org/10.1111/j.1365-2745.2011.01914.x

Lepš, J., de Bello, F., Šmilauer, P., \& Doležal, J. (2011). Community trait response to environment: Disentangling species turnover vs intraspecific trait variability effects. Ecography, 34(5), 856-863. https:// doi.org/10.1111/j.1600-0587.2010.06904.x

Liancourt, P., Boldgiv, B., Song, D. S., Spence, L. A., Helliker, B. R., Petraitis, P. S., \& Casper, B. B. (2015). Leaf-trait plasticity and 
species vulnerability to climate change in a Mongolian steppe. Global Change Biology, 21(9), 3489-3498. https://doi.org/10.1111/ gcb.12934

Lipowsky, A., Roscher, C., Schumacher, J., Michalski, S. G., Gubsch, M., Buchmann, N., Schulze, E.-D., \& Schmid, B. (2015). Plasticity of functional traits of forb species in response to biodiversity. Perspectives in Plant Ecology, Evolution and Systematics, 17(1), 66-77. https://doi.org/10.1016/j.ppees.2014.11.003

Mahaut, L., Fort, F., Violle, C., \& Freschet, G. T. (2020). Multiple facets of diversity effects on plant productivity: Species richness, functional diversity, species identity and intraspecific competition. Functional Ecology, 34(1), 287-298. https://doi.org/10.1111/1365-2435.13473

Mayfield, M. M., \& Levine, J. M. (2010). Opposing effects of competitive exclusion on the phylogenetic structure of communities: Phylogeny and coexistence. Ecology Letters, 13(9), 1085-1093. https://doi org/10.1111/j.1461-0248.2010.01509.x

McDowell, N., Pockman, W. T., Allen, C. D., Breshears, D. D., Cobb, N., Kolb, T., Plaut, J., Sperry, J., West, A., Williams, D. G., \& Yepez, E. A. (2008). Mechanisms of plant survival and mortality during drought: Why do some plants survive while others succumb to drought? New Phytologist, 178(4), 719-739. https://doi. org/10.1111/j.1469-8137.2008.02436.x

McGill, B. J., Enquist, B. J., Weiher, E., \& Westoby, M. (2006). Rebuilding community ecology from functional traits. Trends in Ecology \& Evolution, 21(4), 178-185. https://doi.org/10.1016/j. tree.2006.02.002

Messier, J., McGill, B. J., Enquist, B. J., \& Lechowicz, M. J. (2017). Trait variation and integration across scales: Is the leaf economic spectrum present at local scales? Ecography, 40(6), 685-697. https://doi. org/10.1111/ecog.02006

Mommer, L., \& Weemstra, M. (2012). The role of roots in the resource economics spectrum. New Phytologist, 195(4), 725-727. https://doi. org/10.1111/j.1469-8137.2012.04247.x

Mordecai, E. A. (2011). Pathogen impacts on plant communities: Unifying theory, concepts, and empirical work. Ecological Monographs, 81(3), 429-441. https://doi.org/10.1890/10-2241.1

Petruzzellis, F., Palandrani, C., Savi, T., Alberti, R., Nardini, A., \& Bacaro G. (2017). Sampling intraspecific variability in leaf functional traits: Practical suggestions to maximize collected information. Ecology and Evolution, 7(24), 11236-11245. https://doi.org/10.1002/ece3.3617

Pichon, N. A., Cappelli, S. L., Soliveres, S., Hölzel, N., Klaus, V. H., Kleinebecker, T., \& Allan, E. (2020). Decomposition disentangled: A test of the multiple mechanisms by which nitrogen enrichment alters litter decomposition. Functional Ecology, 34(7), 1485-1496. https://doi.org/10.1111/1365-2435.13560

Poorter, H., Niinemets, Ü., Poorter, L., Wright, I. J., \& Villar, R. (2009) Causes and consequences of variation in leaf mass per area (LMA): A meta-analysis. New Phytologist, 182(3), 565-588. https://doi. org/10.1111/j.1469-8137.2009.02830.x

R. Core Team. (2019). R: A language and environment for statistical computing [Computer software]. Foundation for Statistical Computing.

Ratcliffe, S., Wirth, C., Jucker, T., van der Plas, F., Scherer-Lorenzen, M., Verheyen, K., Allan, E., Benavides, R., Bruelheide, H., Ohse, B., Paquette, A., Ampoorter, E., Bastias, C. C., Bauhus, J., Bonal, D., Bouriaud, O., Bussotti, F., Carnol, M., Castagneyrol, B., ... Baeten, L. (2017). Biodiversity and ecosystem functioning relations in European forests depend on environmental context. Ecology Letters, 20(11), 1414-1426. https://doi.org/10.1111/ele.12849

Ravenek, J. M., Bessler, H., Engels, C., Scherer-Lorenzen, M., Gessler, A., Gockele, A., De Luca, E., Temperton, V. M., Ebeling, A., Roscher, C., Schmid, B., Weisser, W. W., Wirth, C., de Kroon, H., Weigelt, A., \& Mommer, L. (2014). Long-term study of root biomass in a biodiversity experiment reveals shifts in diversity effects over time. Oikos, 123(12), 1528-1536. https://doi.org/10.1111/oik.01502

Rosbakh, S., Römermann, C., \& Poschlod, P. (2015). Specific leaf area correlates with temperature: New evidence of trait variation at the population, species and community levels. Alpine Botany, 125(2), 79-86. https://doi.org/10.1007/s00035-015-0150-6

Roscher, C., Schumacher, J., Gubsch, M., Lipowsky, A., Weigelt, A., Buchmann, N., Schmid, B., \& Schulze, E. (2018). Origin context of trait data matters for predictions of community performance in a grassland biodiversity experiment. Ecology, 99(5), 1214-1226. https://doi.org/10.1002/ecy.2216

Roscher, C., Schumacher, J., Lipowsky, A., Gubsch, M., Weigelt, A., Pompe, S., Kolle, O., Buchmann, N., Schmid, B., \& Schulze, E.-D. (2013). A functional trait-based approach to understand community assembly and diversity-productivity relationships over 7 years in experimental grasslands. Perspectives in Plant Ecology, Evolution and Systematics, 15(3), 139-149. https://doi.org/10.1016/j. ppees.2013.02.004

Rosseel, Y. (2012). lavaan: An R package for structural equation modeling. Journal of Statistical Software, 48(1), 1-36. https://doi. org/10.18637/jss.v048.i02

Sardans, J., Rivas-Ubach, A., \& Peñuelas, J. (2012). The C:N:P stoichiometry of organisms and ecosystems in a changing world: A review and perspectives. Perspectives in Plant Ecology, Evolution and Systematics, 14(1), 33-47. https://doi.org/10.1016/j.ppees.2011.08.002

Shipley, B., \& Almeida-Cortez, J. (2003). Interspecific consistency and intraspecific variability of specific leaf area with respect to irradiance and nutrient availability. Écoscience, 10(1), 74-79. https://doi. org/10.1080/11956860.2003.11682753

Siefert, A., \& Ritchie, M. E. (2016). Intraspecific trait variation drives functional responses of old-field plant communities to nutrient enrichment. Oecologia, 181(1), 245-255. https://doi.org/10.1007/ s00442-016-3563-z

Siefert, A., Violle, C., Chalmandrier, L., Albert, C. H., Taudiere, A., Fajardo, A., Aarssen, L. W., Baraloto, C., Carlucci, M. B., Cianciaruso, M. V., L. Dantas, V., Bello, F., Duarte, L. D. S., Fonseca, C. R., Freschet, G. T., Gaucherand, S., Gross, N., Hikosaka, K., Jackson, B., ... Wardle, D. A. (2015). A global meta-analysis of the relative extent of intraspecific trait variation in plant communities. Ecology Letters, 18(12), 14061419. https://doi.org/10.1111/ele.12508

Stevens, C. J. (2004). Impact of nitrogen deposition on the species richness of grasslands. Science, 303(5665), 1876-1879. https://doi. org/10.1126/science.1094678

Suding, K. N., Collins, S. L., Gough, L., Clark, C., Cleland, E. E., Gross, K. L., Milchunas, D. G., \& Pennings, S. (2005). Functional- and abundance-based mechanisms explain diversity loss due to $\mathrm{N}$ fertilization. Proceedings of the National Academy of Sciences of the United States of America, 102(12), 4387-4392. https://doi.org/10.1073/ pnas.0408648102

van der Plas, F., Schröder-Georgi, T., Weigelt, A., Barry, K., Meyer, S., Alzate, A., Barnard, R. L., Buchmann, N., de Kroon, H., Ebeling, A., Eisenhauer, N., Engels, C., Fischer, M., Gleixner, G., Hildebrandt, A., Koller-France, E., Leimer, S., Milcu, A., Mommer, L., ... Wirth, C. (2020). Plant traits alone are poor predictors of ecosystem properties and long-term ecosystem functioning. Nature Ecology \& Evolution, 4(12), 1602-1611. https://doi.org/10.1038/s41559-02001316-9

Violle, C., Enquist, B. J., McGill, B. J., Jiang, L., Albert, C. H., Hulshof, C., Jung, V., \& Messier, J. (2012). The return of the variance: Intraspecific variability in community ecology. Trends in Ecology \& Evolution, 27(4), 244-252. https://doi.org/10.1016/j.tree.2011.11.014

Vitousek, P. M., Aber, J. D., Howarth, R. W., Likens, G. E., Matson, P. A., Schindler, D. W., Schlesinger, W. H., \& Tilman, D. G. (1997). Human alteration of the global nitrogen cycle: Sources and consequences. Ecological Applications, 7(3), 737-750. https:// doi.org/10.1890/1051-0761(1997)007\%5B073 7:HAOTG N\%5D2.0.CO;2

Vogel, A., Manning, P., Cadotte, M. W., Cowles, J., Isbell, F., Jousset, A. L. C., Kimmel, K., Meyer, S. T., Reich, P. B., Roscher, C., SchererLorenzen, M., Tilman, D., Weigelt, A., Wright, A. J., Eisenhauer, N., 
\& Wagg, C. (2019). Chapter Three - Lost in trait space: Speciespoor communities are inflexible in properties that drive ecosystem functioning. In N. Eisenhauer, D. A. Bohan, \& A. J. Dumbrell (Eds.), Advances in ecological research (Vol. 61, pp. 91-131). Academic Press. https://doi.org/10.1016/bs.aecr.2019.06.002

Walde, M., Allan, E., Cappelli, S. L., Didion-Gency, M., Gessler, A., Lehmann, M. M., Pichon, N. A., \& Grossiord, C. (2021). Both diversity and functional composition affect productivity and water use efficiency in experimental temperate grasslands. Journal of Ecology, 109(11), 3877-3891. https://doi.org/10.1111/1365-2745.13765

Wright, I. J., Reich, P. B., Westoby, M., Ackerly, D. D., Baruch, Z., Bongers, F., Cavender-Bares, J., Chapin, T., Cornelissen, J. H. C., Diemer, M., Flexas, J., Garnier, E., Groom, P. K., Gulias, J., Hikosaka, K., Lamont, B. B., Lee, T., Lee, W., Lusk, C., ... Villar, R. (2004). The worldwide leaf economics spectrum. Nature, 428(6985), 821-827. https://doi. org/10.1038/nature02403

Zuur, A., leno, E. N., Walker, N., Saveliev, A. A., \& Smith, G. M. (2009). Mixed effects models and extensions in ecology with $R$. SpringerVerlag. https://doi.org/10.1007/978-0-387-87458-6

\section{SUPPORTING INFORMATION}

Additional supporting information may be found in the online version of the article at the publisher's website.

How to cite this article: Pichon, N. A., Cappelli, S. L., \& Allan, E. (2021). Intraspecific trait changes have large impacts on community functional composition but do not affect ecosystem function. Journal of Ecology, 00, 1-15. https://doi. org/10.1111/1365-2745.13827 